\title{
Luteolin inhibits proliferation, triggers apoptosis and modulates Akt/mTOR and MAP kinase pathways in HeLa cells
}

\author{
RITU RAINA $^{1 *}$, SREEPOORNA PRAMODH ${ }^{2 *}$, NAUSHAD RAIS $^{1}$, SHAFIUL HAQUE $^{3}$, \\ JASMIN SHAFARIN $^{4}$, KHULOUD BAJBOUJ ${ }^{4}$, MAWIEH HAMAD ${ }^{4}$ and ARIF HUSSAIN ${ }^{1}$
}

\author{
${ }^{1}$ School of Life Sciences, Manipal Academy of Higher Education; ${ }^{2}$ Department of Life and Environmental Sciences, \\ College of Natural and Health Science, Zayed University, Dubai, United Arab Emirates; ${ }^{3}$ Research and Scientific Studies Unit, \\ College of Nursing and Allied Health Sciences, Jazan University, Jazan 45142, Saudi Arabia; ${ }^{4}$ College of Medicine, \\ University of Sharjah, Sharjah, United Arab Emirates
}

Received July 22, 2020; Accepted November 9, 2020

DOI: 10.3892/ol.2021.12452

\begin{abstract}
Flavonoids, a subclass of polyphenols, have been shown to be effective against several types of cancer, by decreasing proliferation and inducing apoptosis. Therefore, the aim of the present study was to assess the anti-carcinogenic potential of luteolin on HeLa human cervical cancer cells, through the use of a cell viability assay, DNA fragmentation assay, mitochondrial membrane potential assay, cell cycle analysis using Annexin/PI staining and flow cytometry, gene expression analysis and a protein profiling array. Luteolin treatment exhibited cytotoxicity towards HeLa cells in a dose- and time-dependent manner, and its anti-proliferative properties were confirmed by accumulation of luteolin-treated cells in sub- $\mathrm{G}_{1}$ phases. Cytotoxicity induced by luteolin treatment resulted in apoptosis, which was mediated through depolarization of the mitochondrial membrane potential and DNA fragmentation. Furthermore, luteolin treatment increased the expression of various proapoptotic genes, including $A P A F 1, B A X, B A D, B I D$, $B O K, B A K 1, T R A D D, F A D D, F A S$, and Caspases 3 and 9, whereas the expression of anti-apoptotic genes, including $N A I P, M C L-1$ and $B C L-2$, was decreased. Cell cycle regulatory genes, including $C C N D 1,2$ and 3,CCNE2, CDKN1A, $C D K N 2 B, C D K 4$ and $C D K 2$, were decreased following
\end{abstract}

Correspondence to: Dr Arif Hussain, School of Life Sciences, Manipal Academy of Higher Education, Block A, P.O. Box 345050, Academic, Dubai, United Arab Emirates

E-mail: dr.arifhussain@yahoo.co.in

Dr Sreepoorna Pramodh, Department of Life and Environmental Sciences, College of Natural and Health Science, Zayed University, P.O. Box 19282, Academic, Dubai, United Arab Emirates

E-mail: sreepoorna.Unni@zu.ac.ae

${ }^{*}$ Contributed equally

Key words: cancer, apoptosis, anticancer, chemoprevention, antiproliferation treatment. Expression of TRAILR2/DR5, TRAILR1/DR4, Fas/TNFRSF6/CD95 and TNFR1/TNFRSF1A, as well as pro-apoptotic proteins, including BAD, BAX and Cytochrome $\mathrm{C}$ were consistently increased, and the expression of antiapoptotic proteins, HIF1 $\alpha$, BCL-X, MCL1 and BCL2, were found to be decreased following treatment. Expression of $A K T 1$ and 2, ELK1,PIK3C2A, PIK3C2B, MAPK14, MAP3K5, $M A P K 3$ and $M A P K 1$ was significantly decreased at the transcriptional level. Expression of GSK3b (p-ser9), PRAS 40 (p-Ther246), BAD (p-ser112), PTEN (p-ser380), AKT (p-ser473), ERK2 (p-Y185/Y187), RISK2 (p-ser386), P70S6k (p-Thr421/ser424), PDK1(p-ser241), ERK1 (p-T202/Y204) and MTOR (p-ser2448) was downregulated and expression of P53 (p-ser241) and P27(p-Thr198) was upregulated by luteolin in a dose-dependent manner, indicating its anti-proliferative and apoptosis enabling properties, and this may have been mediated via inhibition of the AKT and the MAPK pathways.

\section{Introduction}

A major challenge with conventional cancer treatments, including chemotherapy, is the genotypic and phenotypic heterogeneity of cancer cells, and non-selective cytotoxicity of these treatment regimens, and this limits their use, increasing the risk of cancer reoccurrence $(1,2)$. Therefore, experimental evidences need to be accumulated on plant-derived chemopreventative strategies, which may be used as adjuvants for improved cancer management. Chemopreventative agents (synthetic and natural) consist of nonsteroidal anti-inflammatory drugs (sulindac, aspirin and celecoxib) (3) and FDA-approved drugs, including Tamoxifen, Raloxifene and HPV vaccines (Cervarix and Gardasil), which all show potential anticancer effects. However, these adjuvants have also demonstrated adverse side effects in patients (4-6). Considering the constraints of these agents, studies are focused on identifying alternatives based on plant-derived compounds, which exhibit decreased toxicity with higher efficacy for the treatment of cancer (7-9).

Notably, an epidemiological study proposed that $30 \%$ of cancer types can be avoided by a healthy diet (2), and the consumption of certain fruits and vegetables may decrease 
the risk of cancer onset $(5,10,11)$. Several flavonoids extracted from various plants have been shown to exert anticancer properties $(5,7)$, exhibiting regulatory effects on several molecular mechanisms, including their ability to increase the activity of free radical scavenging enzymes, and increase anti-proliferative and anti-inflammatory responses $(7,12,13)$. Furthermore, flavones, a subclass of flavonoids have been demonstrated to possess anticancer effects through decreasing cancer cell proliferation by downregulation of various pro-apoptotic proteins, including nuclear factor- $\kappa \mathrm{B}$ along with modulation of aberrant PI3K/AKT and MAPK/P38 signaling (14-18). Apoptosis is the desired outcome when treated with these agents, and if the means by which apoptosis is induced is determined, the efficacy of novel agents targeting these mechanisms may be assessed. Apoptosis is primarily mediated by the death receptor pathway and mitochondrial pathway. The death receptor family, which is comprised of tumor necrosis factor receptors, including TRAIL-R2/DR5, TRAIL-R1/DR4, TNFRI/TNFRSF1A, Fas/TNFRSF6/CD95, Fas and DR6 may initiate the extrinsic pathway, and BCL2 family members, including Bad, Bak, Bax, Bid, Bik (pro-apoptotic molecules), and Bcl-XL and Bcl-2 (anti-apoptotic members) are involved in the mitochondrial pathway (19-21).

Luteolin (3,4,5,7-tetrahydroxy flavone) is a flavone found in vegetables and fruits, including parsley, carrots, artichoke, celery and several spices (including thyme and oregano) $(14,16,17,22-25)$. Several studies have demonstrated the anti-inflammatory, anti-microbial, anti-diabetic and anti-carcinogenic properties of luteolin $(23,26-28)$. Luteolin has been demonstrated to exhibit anticancer effects against several types of cancer cell lines, including liver (HepG2), colon (HT29), lung (LNM35) and breast cancer (MDA-MB-231) cells, and is a potent HDAC inhibitor $(16,19)$. Luteolin induces apoptosis and cell cycle arrest by increasing expression of Bax, Caspase 3 and Caspase 9, as well as the MEK-ERK pathway, whilst concomitantly decreasing Bcl-2 expression in A549 lung cancer cells (18). Luteolin also possesses anti-proliferative effects against A549 lung cancer cells by arresting the cell cycle at the $\mathrm{G} 2$ phase and initiating programmed cell death via the mitochondrial pathway, which is mediated though activation of JNK and inhibition of NF- $\mathrm{B}(22,29)$. Luteolin suppresses the MAPK/AKT/PI3K pathway, and NF-kB and STAT3 signalling in several types of cancer cell lines, and also decreases the expression of matrix metalloproteins and $\beta 3$ integrin in B16F10 and A431 melanoma cell lines, thereby inhibiting EMT $(17,20,22,24,30,31)$.

Notably, flavonoids including luteolin have been reported to inhibit tumor cell proliferation and apoptosis (14-19) in various cancer cell lines e.g., HPV-18-associated cells and lung cancer cell $(17,18)$. However, there is lack of scientific evidence to review luteolin as a probable anticancer agent. Therefore, the present study aimed to investigate the extensive molecular mechanism through which luteolin induces anticancer effects on HeLa cell as an apoptosis inducer by targeting various molecular targets; tumor inhibitors and promoters: $D A P K 1$, TP53, TP73, PTPRRR and TERT; cell cycle regulatory genes: $C D K 2$, $C C N E 2, C C N D 2$ and $C C N D$; pro and anti-apoptotic genes: $B A D, B I D, B O K, B A X, B c l 2$, Caspases 3, 7, 8 and 9; receptors and pathways genes: FASLG, FAS, TNFRS10-B, MTOR, MAPK, PIK3CA, AKT1, ELK1, FOXO1 and FOXO3, and to further associate it with the modulation of phosphorylated proteins in luteolin-treated HeLa cells to enhance the acceptance of luteolin as a potential anticancer agent.

\section{Material and methods}

Cell culture and drug preparation. Information of every important process that ensues in human cells whether normal or abnormal has depended to a large extent on using HeLa cells and they have also proved to be the best model for cervical cancer (32); therefore, HeLa cells were used for this study. Human cervical cancer HeLa cells were cultured in Dulbecco's modified Eagle's medium (DMEM; Sigma-Aldrich; Merck KGaA), supplemented with $10 \%$ FBS (Sigma-Aldrich; Merck $\mathrm{KGaA}$ ), $100 \mu \mathrm{g} / \mathrm{ml}$ amphotericin (Sigma-Aldrich; Merck $\mathrm{KGaA}$ ) and $100 \mu \mathrm{g} / \mathrm{ml}$ streptomycin (Sigma-Aldrich; Merck $\mathrm{KGaA}$ ), and cells were cultured at $37^{\circ} \mathrm{C}$ in a humidified incubator with $5 \% \mathrm{CO}_{2}$.

Luteolin (molecular weight, $286.24 \mathrm{~g} / \mathrm{mol}$ ) was purchased from Sigma-Aldrich (Merck KGaA) and diluted to a concentration of $69.87 \mathrm{mM}$ using dimethyl sulfoxide (DMSO; stock solution), which was then further diluted using DMEM (without FBS) to a concentration of $1 \mathrm{mM}$, which was used to make the working concentrations of $1-40 \mu \mathrm{M}$.

MTT assay. MTT assay (Sigma-Aldrich; Merck KGaA) was used to study the cytotoxic effects of luteolin on HeLa cells. In brief, $1 \times 10^{4}$ cells/well were plated onto a 96-well plate and treated as follows: Blank control, DMSO control (0.11\%), positive control (cisplatin $5 \mu \mathrm{M})$ and luteolin-treated $(1-40 \mu \mathrm{M})$; and treatment was performed for 24 or $48 \mathrm{~h}$, after which images were captured. Subsequently, plates were decanted, and the cells were incubated with MTT at final concentration of $5 \mathrm{mg} / \mathrm{ml}$ (dissolved in PBS) at $37^{\circ} \mathrm{C}$ for $2-4 \mathrm{~h}$, the MTT was discarded, $100 \mu \mathrm{l}$ DMSO was added to the wells and plates were incubated at $37^{\circ} \mathrm{C}$ for $30 \mathrm{~min}$ in the dark. Viable cells convert the tetrazolium salt into insoluble formazan violet crystals that is quantified using a colorimeter at $570 \mathrm{~nm}$. A graph was plotted by dividing the absorbance of luteolin-treated cells with that of DMSO controls. Data are presented as the mean \pm standard deviation of three independent repeats.

Nuclear staining of HeLa cells with propidium iodide (PI) following luteolin treatment. PI staining of cells treated with luteolin for different concentrations was performed to assess morphological variations in the nucleus in cells undergoing apoptosis. In total, $\sim 2.5 \times 10^{5}$ cells were seeded onto glass coverslips and treated with luteolin for 24 or $48 \mathrm{~h}$. The cells were then washed with 1x PBS ( $\mathrm{pH} 7.4)$ twice and a mixture of ice cold methanol:acetone (1:1) was used to fix the cells at $-20^{\circ} \mathrm{C}$ for $10 \mathrm{~min}$ followed by staining with PI $(10 \mathrm{mg} / \mathrm{ml}$ in PBS) for $30 \mathrm{sec}$ in the dark at room temperature, and the cover slips were subsequently mounted on glass slides. The images were captured at $515 \mathrm{~nm}$ using a fluorescent microscope (Olympus Corporation) at x40 magnification.

DNA fragmentation assay. Inter-nucleosomal DNA disintegration is one of the primary features of apoptosis. During apoptosis, nucleases are activated causing fragmentation of nuclear chromatin into 50-300 kbp fragments (33). The 
ApoTarget $^{\mathrm{TM}}$ Quick Apoptotic DNA Ladder Detection kit (cat. no. \#KHO1021; Invitrogen; Thermo Fisher Scientific, Inc.) was used for rapid extraction of chromosomal DNA of untreated cells, and cells treated with 5, 10 and $20 \mu \mathrm{M}$ luteolin for $48 \mathrm{~h}$, according to the manufacturer's protocol. The fragmented DNA was extracted from cells and run on a horizontal electrophoresis gel containing ethidium bromide and the DNA was resolved on a $1.2 \%$ agarose gel.

Tetramethyl rhodamine, ethyl ester (TMRE) mitochondrial membrane potential assay. A TMRE Mitochondrial Membrane Potential assay kit (cat. no. ab113852; Abcam) was used to assess the mitochondrial membrane potential. In total, $\sim 5 \times 10^{3}$ HeLa cells were plated onto clear bottom 96 -well plates and treated with 5, 10 and $20 \mu \mathrm{M}$ luteolin for $48 \mathrm{~h}$ at room temperature. TMRE at a final concentration of $400 \mathrm{nM}$ was used and the cells were incubated in the dark for $30 \mathrm{~min}$ at room temperature. Following washing several times with the wash buffer provided with the aforementioned kit, the plate was read on a fluorescence microplate spectrophotometer $(E x / E m=549 / 575$ nm; Synergy H1 Bioteck Plate Reader) and images were captured using a fluorescent microscope (Progress Fluorescent Microscope; Olympus Corporation) at x40 magnification.

Apoptosis detection using FITC-conjugated Annexin VIPI. Quantitation of the apoptosis was performed using a FITC-conjugated Annexin V/PI assay kit (cat. no. ab 14085; Abcam) and analyzed using a flow cytometer. In brief, $2 \times 10^{5}$ cells were plated onto six-well plates, and cells were treated with 5,10 and $20 \mu \mathrm{M}$ luteolin for $48 \mathrm{~h}$ at $37^{\circ} \mathrm{C}$. Treated and untreated cells were collected and washed with PBS and resuspended in $500 \mu \mathrm{l}$ binding buffer, followed by staining with PI $(50 \mu \mathrm{g} / \mathrm{ml})$ and FITC-conjugated Annexin V $(10 \mathrm{mg} / \mathrm{ml})$ for $15 \mathrm{~min}$ at room temperature in the dark, and the cells were analyzed using a BD FACS-Aria ${ }^{\mathrm{TM}}$ III Flow cytometer (BD Biosciences). Flow cytometry data were analyzed using the FlowJo software (FlowJo LLC; Version 10.1).

Cell cycle analysis by flow cytometry. HeLa cells were treated with $0,5,10$ and $20 \mu \mathrm{M}$ luteolin for $48 \mathrm{~h}$, and all the cells (floating and attached) were collected. This was followed by washing with $1 \mathrm{x}$ PBS and fixed with absolute ethanol at $-20^{\circ} \mathrm{C}$ overnight. The following day, cells were washed with 1x PBS and staining with PI $(1 \mathrm{mg} / \mathrm{ml})$, containing $0.1 \%$ citrate buffer, Triton X-100 and $0.5 \%$ RNase for $30 \mathrm{~min}$ at room temperature. BD FACS-Aria ${ }^{\mathrm{TM}}$ III Flow cytometer (BD Biosciences) was used to analyze the cells for DNA content, and FlowJo software (FlowJo LLC; version 10.1) was used for data analysis.

Gene expression analysis using TaqManarrays. RNA extraction was performed on luteolin-treated HeLa cells (10 and $20 \mu \mathrm{M}$ for $48 \mathrm{~h}$ at $37^{\circ} \mathrm{C}$ ) and untreated cells according to the manufacturer's protocol using a GenElute Mammalian Genomic Total RNA kit (Sigma-Aldrich; Merck KGaA). Extracted total RNA was quantified using Nanodrop (Thermo Fisher Scientific, Inc.). RNA was then subjected to first strand synthesis, according to the manufacturer's protocol, using an Applied Biosystems ${ }^{\mathrm{TM}}$ High-Capacity cDNA Reverse Transcription kit (Applied Biosystems; Thermo Fisher Scientific, Inc.).
TaqMan ${ }^{\circledR}$ Gene Expression assays are a comprehensive collection of pre-designed, pre-formulated primer and probe sets to perform quantitative gene expression studies (Apoptosis Array and oncogene array (cat. nos. 4414072 and 4391524). TaqMan ${ }^{\circledR}$ Gene Expression assays that were manufactured and stocked in advance were used to detect the expression of genes associated with cell cycle signaling pathways and apoptosis in the treated and untreated cells. A total of $10 \mu \mathrm{l}$ cDNA with a concentration of $100 \mathrm{ng}$ per well and $10 \mu \mathrm{l}$ master mix provided in the kit was used. Expression analysis was performed according to the manufacturer's protocol. The qPCR array was run on a thermocycler (QuantiStudio3, Applied Biosystems, USA) with the following reaction conditions: Enzyme activation at $95^{\circ} \mathrm{C}$ for $10 \mathrm{~min}$ and 40 cycles, denaturation at $95^{\circ} \mathrm{C}$ for $15 \mathrm{sec}$, annealing at $60^{\circ} \mathrm{C}$ for $1 \mathrm{~min}$. Results were analyzed by the $2^{-\Delta \Delta \mathrm{Cq}}$ method using DataAssist ${ }^{\mathrm{TM}}$ software version 3.01 (Thermo Fisher Scientific, Inc.) as previously described (34).

Caspase 3 activity. Caspases are the final executioners of apoptosis and Caspase-3 serves a role in the extrinsic and intrinsic pathways of apoptosis (35). A Caspase-3 Activity kit (cat. no. CASP 3C; Sigma-Aldrich; Merck KGaA) was used. A total of $1 \times 10^{6}$ cells were plated and treated $(5,10$ and $20 \mu \mathrm{M}$ luteolin at $37^{\circ} \mathrm{C}$ for $48 \mathrm{~h}$ ) with various concentrations of luteolin. Cell pellets were taken and resuspended in the lysis buffer (1X) at a concentration of $1 \mathrm{X} 10^{7}$ cell/100 $\mu \mathrm{l}$ and incubated for $30 \mathrm{~min}$, prior to being centrifuged at $12,000 \mathrm{x} \mathrm{g}$ for $20 \mathrm{~min}$ at $4^{\circ} \mathrm{C}$. The lysates of the DMSO control and treated (5, 10 and $20 \mu \mathrm{M}$ luteolin) HeLa cells and the assay were set up according to the manufacturers' protocol. The plate was incubated overnight at room temperature and read at $405 \mathrm{~nm}$, and fold-changes were calculated by comparing the treated sample reading with the DMSO control. The experiment was repeated 3 times and all results are expressed as mean \pm standard deviation of three independent experiments.

Determination of protein expression using a proteome profiler array. To determine the expression of genes associated with apoptosis and cell cycle progression at the protein level, a protein profiler array was purchased from R\&D Systems, Inc. (cat. no. ARY009). The cells were treated with 10 and $20 \mu \mathrm{M}$ luteolin for $48 \mathrm{~h}$ at $37^{\circ} \mathrm{C}$ and the lysis was performed with lysis buffer. The assay was performed according to the manufacturer's protocol to assess the expression of all the proteins associated with apoptosis. Protein quantitation of lysates was performed using a Pierce ${ }^{\mathrm{TM}}$ BCA Protein assay kit (Thermo Fisher Scientific, Inc; cat. no. 23225). A further $400 \mu \mathrm{g}$ protein of the diluted cell lysate was used for each membrane, the membranes were incubated with the lysates on a rocking platform overnight at $2-8^{\circ} \mathrm{C}$. The signal was developed using Streptavidin-HRP and chemiluminescent detection reagents. Signal intensity was measured using a chemiluminescent detector Gel Doc system (Bio-Rad Laboratories, Inc.), and analyzed using Image Lab software (version 6.1; Bio-Rad Laboratories, Inc.). The experiment was repeated three times and the results are expressed as the mean \pm standard deviation from three independent experiments $\left({ }^{*} \mathrm{P}<0.005\right)$.

Analysis of expression of phosphorylated AKT pathway proteins. To determine the effect of luteolin treatment on 


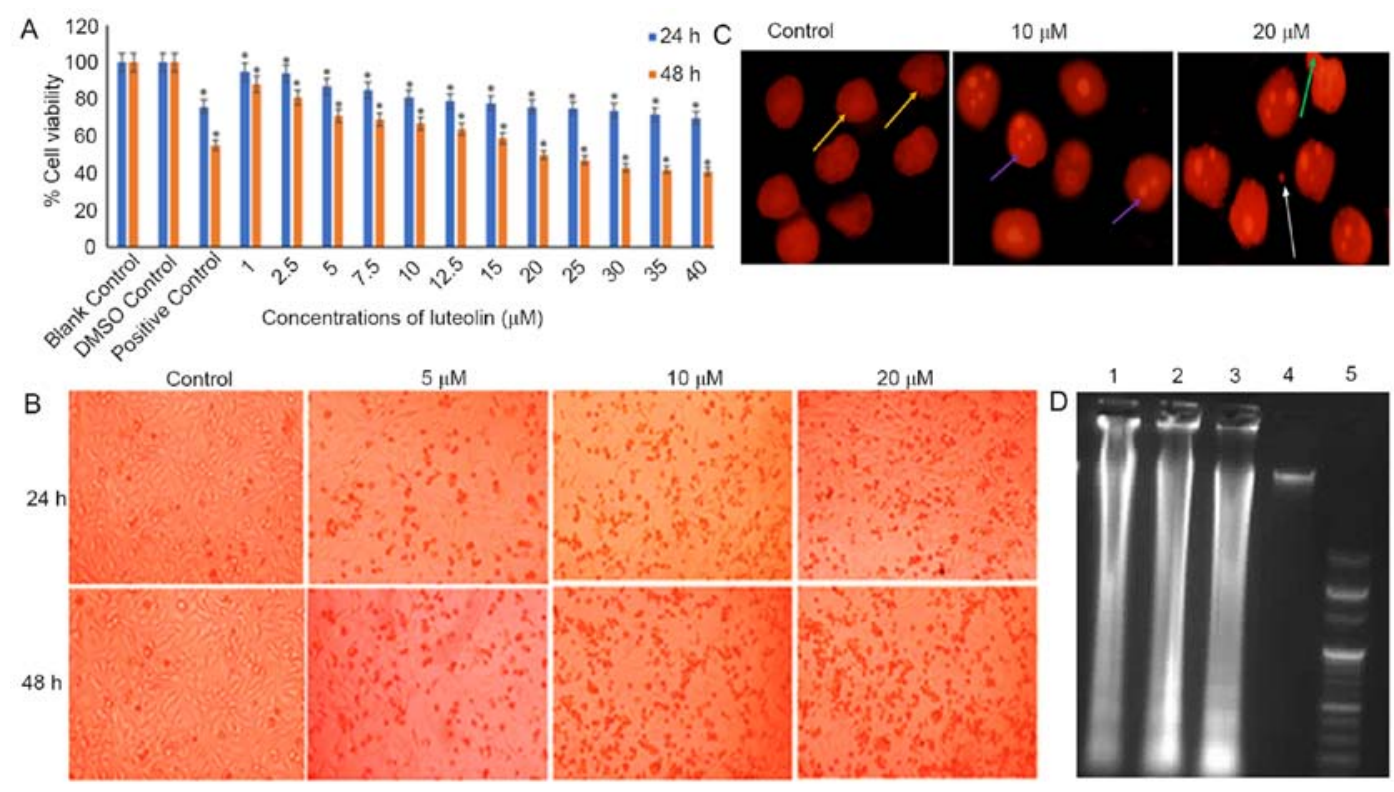

Figure 1. Anti-proliferative effect of luteolin on HeLa cells. (A) Induction of cytotoxicity by luteolin at various concentrations and time points. The graph represents the dose- and time-dependent decrease in cell viability of HeLa cells treated with 1-40 $\mu \mathrm{M}$ luteolin for 24 and $48 \mathrm{~h}$. For comparison, $0.11 \%$ DMSO was used as the loading control and $5 \mu \mathrm{M}$ cisplatin was used as the positive control. The 24 and $48 \mathrm{~h}$ treated samples were compared with 24 and $48 \mathrm{~h}$ DMSO controls, respectively. The data are expressed as the mean \pm standard deviation of three independent experiments. ${ }^{*} \mathrm{P}<0.05$. The $\mathrm{IC}_{50}$ of luteolin was found to be $20 \mu \mathrm{M}$ at $48 \mathrm{~h}$. (B) Microscopic images of HeLa cells treated with 10,15 and $20 \mu \mathrm{M}$ luteolin for 24 and $48 \mathrm{~h}$. Cells exhibited a characteristic rounding off of the cells, indicating apoptosis. Magnification, x10. (C) Changes in nuclear morphology of treated HeLa cells (10 and $20 \mu \mathrm{M}$ luteolin) compared with the untreated controls. These nuclear changes were observed following staining with propidium iodide under a fluorescence microscope (magnification, $\mathrm{x} 40$ ). A dose-dependent increase in the apoptotic index, characterized by features such as nuclear condensation, nuclear blebbing, nuclear fragmentation and apoptotic bodies, was observed. Yellow, large and prominent nuclei; purple, nuclear fragmentation; green, blebbing; white, apoptotic bodies. (D) Luteolin induces DNA fragmentation in a dose-dependent manner in HeLa cells. Lane 5 shows the 100 bp ladders; lanes 1, 2, 3 and 4 show fragmentation of DNA in cells treated with 5,10 and $20 \mu \mathrm{m}$ luteolin and the control, respectively. The experiment was performed three times. DMSO, dimethyl sulfoxide.

proteins involved in the AKT pathway, a phosphorylated AKT pathway array was obtained from Ray-Biotech, Co., Ltd. (cat. no. AAH-AKT-1-8). The lysates of treated and untreated cells were quantitated using a Pierce BCA assay (Thermo Fisher Scientific, Inc.) and $\sim 500 \mu \mathrm{g}$ lysate was used on each nitrocellulose membrane. To begin with, the membranes were blocked with blocking buffer from the aforementioned kit, followed by incubation with the cell lysate for $24 \mathrm{~h}$, and the assay was performed according to the manufacturer's protocol. The chemiluminescent gel doc system (BioRad Laboratories, Inc.) was used to capture the image of the blot and analysis was performed using Image Lab software (version 6.1).

Statistical analysis. Statistical analysis was performed using SPSS software (version 21; IBM Corp.). The data was analyzed using one-way analysis of variance followed by Tukey's HSD post hoc test. All experiments were performed in triplicate. Results are expressed as the mean \pm standard deviation of three separate experiments ${ }^{*} \mathrm{P}<0.05$ was considered to indicate a statistically significant difference.

\section{Results}

Luteolin inhibits the growth and proliferation of HeLa cells. HeLa cells treated with varying concentrations of luteolin (1-40 $\mu \mathrm{M}$ for 24 or $48 \mathrm{~h}$ ) exhibited a dose and time-dependent decrease in the viability of HeLa cells when compared with the untreated DMSO control. When cells were treated with $20 \mu \mathrm{M}$ luteolin for $48 \mathrm{~h}, \sim 50 \%$ cell death was observed (Fig. 1A).
Luteolin induced substantial morphological changes in HeLa cells, including rounding off of the cells and subsequent detachment of the cells from the surface, and the changes became more significant as the dose of luteolin was increased (Fig. 1B).

Luteolin induces nuclear morphological abnormalities and causes DNA fragmentation in HeLa cells. HeLa cells treated with 10 and $20 \mu \mathrm{M}$ luteolin exhibited condensation and disintegration of nuclear material, blebbing and formation of apoptotic bodies and nuclear debris, which increased with concentration, while the untreated HeLa cells possessed a distinct and prominent nucleus (Fig. 1C). Furthermore, the observation that luteolin induced apoptosis was supported by the results of a DNA laddering assay in HeLa cells. Treatment of HeLa cells with 5, 10 and $20 \mu \mathrm{M}$ luteolin for $48 \mathrm{~h}$ resulted in fragmentation of DNA. A typical DNA ladder-like pattern was observed in all the treated samples when compared with the controls upon gel electrophoresis (Fig. 1D).

Luteolin treatment arrests cell cycle progression of HeLa cells at sub-G1 phases. Inhibition of proliferation and growth may be a result of cell cycle arrest. Analysis of cell cycle progression was performed on luteolin-treated cells using PI staining and flow cytometry. Luteolin induced accumulation of cells at the $\mathrm{G} 2 / \mathrm{M}$ phase when treated with $5 \mu \mathrm{M}$, and when treated with 10 and $20 \mu \mathrm{M}$, accumulation of cells was observed at sub-G1 phases, and $\sim 50 \%$ of cells were arrested when treated with $20 \mu \mathrm{M}$ luteolin for $48 \mathrm{~h}$, with a decrease in the number of 

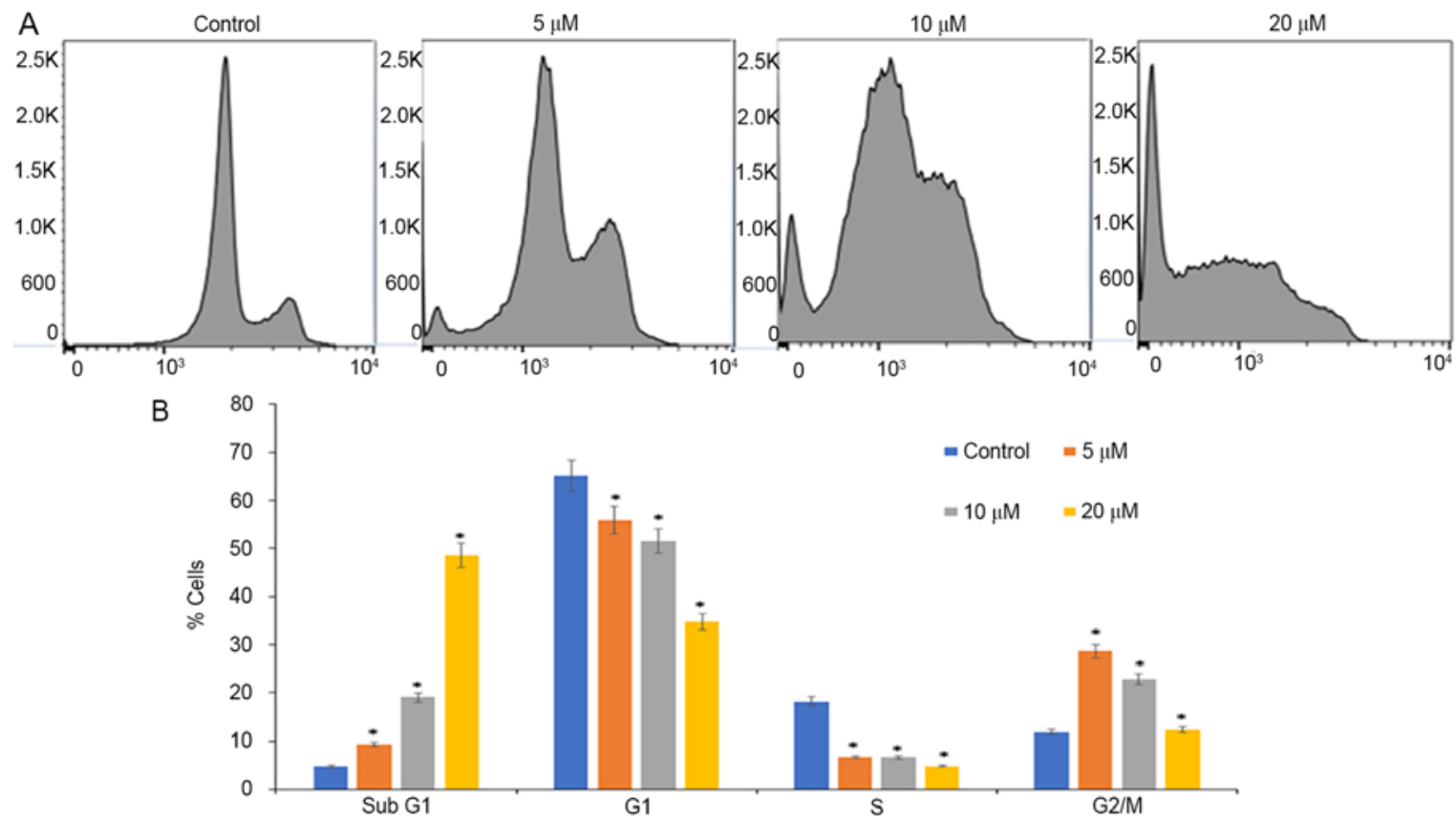

Figure 2. Luteolin induces cell cycle arrest in HeLa cells in sub-G1 phases. (A) DNA contents were analyzed by flow cytometry following treatment with different concentrations of luteolin $(0,5,10$ and $20 \mu \mathrm{M})$ for $48 \mathrm{~h}$. (B) Percentage of cells in the G0/G1, S and G2/M phases of the cell cycle are compared between the 5, 10,20 $\mu \mathrm{M}$ treated HeLa cells and dimethyl sulfoxide control cells. The results are presented as the mean \pm standard deviation of three independent experiments ${ }^{*} \mathrm{P}<0.05$.

cells in the $\mathrm{S}$ and $\mathrm{G} 2 / \mathrm{M}$ phases when compared with controls wherein a normal distribution of cells was observed (Fig. 2). In the present study, luteolin treatment increased the sub-G1 peak, which is an indicator of endonuclease activation and apoptosis induction due to DNA fragmentation, which appears to be the crucial anti-proliferative mechanism of luteolin treatment (36).

Luteolin induces early and late apoptosis. Annexin V-FITC and PI were used for the detection of early and late apoptosis. Annexin V-stained cells were considered early apoptotic cells, and cells stained with PI and annexin V and were considered late apoptotic cells. The percentage of viable cells decreased from $90.5 \%$ in the control cells to 65.4 and $47.9 \%$ when treated with 10 and $20 \mu \mathrm{M}$ luteolin, respectively, for $48 \mathrm{~h}$. Additionally, there was an increase in early apoptotic cells from $2.89 \%$ in control samples to 9.75 and $12.4 \%$ when treated with 10 and $20 \mu \mathrm{M}$ luteolin. A notable increase in the proportion of late apoptotic cells was detected, increasing from $1.89 \%$ in in the untreated samples to 7.85 and $14 \%$ when treated with 10 and $20 \mu \mathrm{M}$ luteolin 48 h, respectively (Fig. 3).

Luteolin decreases the mitochondrial membrane potential of HeLa cells. Mitochondrial membrane potential is a reliable measure of cell stress and apoptosis, as it is compromised early during the stress response and a good indicator of ongoing cell death. Several dyes may be used to detect mitochondrial membrane potential, which allows flexibility in wavelengths and use in combination with other fluorescence markers. In the present study, TMRE was used. The percentage of TMRE fluorescence was calculated compared with the control; 84, 64 and $56 \%$ of cells fluoresced with TMRE when HeLa cells were treated with 5,10 and $20 \mu \mathrm{M}$ luteolin for $48 \mathrm{~h}$, respectively (Fig. 4).

Luteolin inhibits cell cycle progression by modulation of cell cycle regulatory genes. Following treatment of HeLa cells with 5,10 and $20 \mu \mathrm{M}$ luteolin for $48 \mathrm{~h}$, the untreated and treated cells were subjected to cell cycle progression analysis. The results demonstrated that $5 \mu \mathrm{M}$ luteolin induced $\mathrm{G} 2 / \mathrm{M}$ phase arrest in HeLa cells, and when treated with $20 \mu \mathrm{M}$ luteolin, there was a substantial accumulation of cells at sub G1 phases. This was further verified by assessing the expression of cell cycle regulatory genes (oncogene array, cat. no. 4369514); downregulation of cell cycle regulatory genes, including $C C N D 1$, $C C N D 2, C C N D 3, C C N E 2, C D K N 1 A, C D K N 2 B, C D K 4$ and $C D K 2$, was observed. All these genes serve an important role in the G1 phase transition. Additionally, telomerase reverse transcriptase (TERT) expression was decreased and PTPRR expression was significantly increased when treated with 10 and $20 \mu \mathrm{M}$ luteolin. TERT adds repeat sequences of DNA (TTAGGG) to the end of chromosomes, thereby increasing the replicative properties, and its inhibition controls proliferation, while PTPRR inhibits ERK and MAPK pathways. FOXO1 and FOXO3 expression was also upregulated, and they serve an important role in apoptosis [Fig. 5A; RQ (relative quantitation)] values are presented in Table I).

Luteolin increases apoptosis in HeLa cells. HeLa cells treated with 10 and $20 \mu \mathrm{M}$ luteolin for $48 \mathrm{~h}$ along with untreated cells were used to assess gene expression of apoptotic genes using a TaqMan Array (apoptosis array; cat. no. 4414072). Gene expression levels of $A P A F 1, B I D, B A K 1, B O K, B A D, B A X$, NOD1, NOD2, BCL10 and BCL2L14, as well as Caspase-3, Caspase-7 and Caspase-9 increased (10 $\mu \mathrm{M}, \mathrm{RQ} \geq 1.4 ; 20 \mu \mathrm{M}$, 

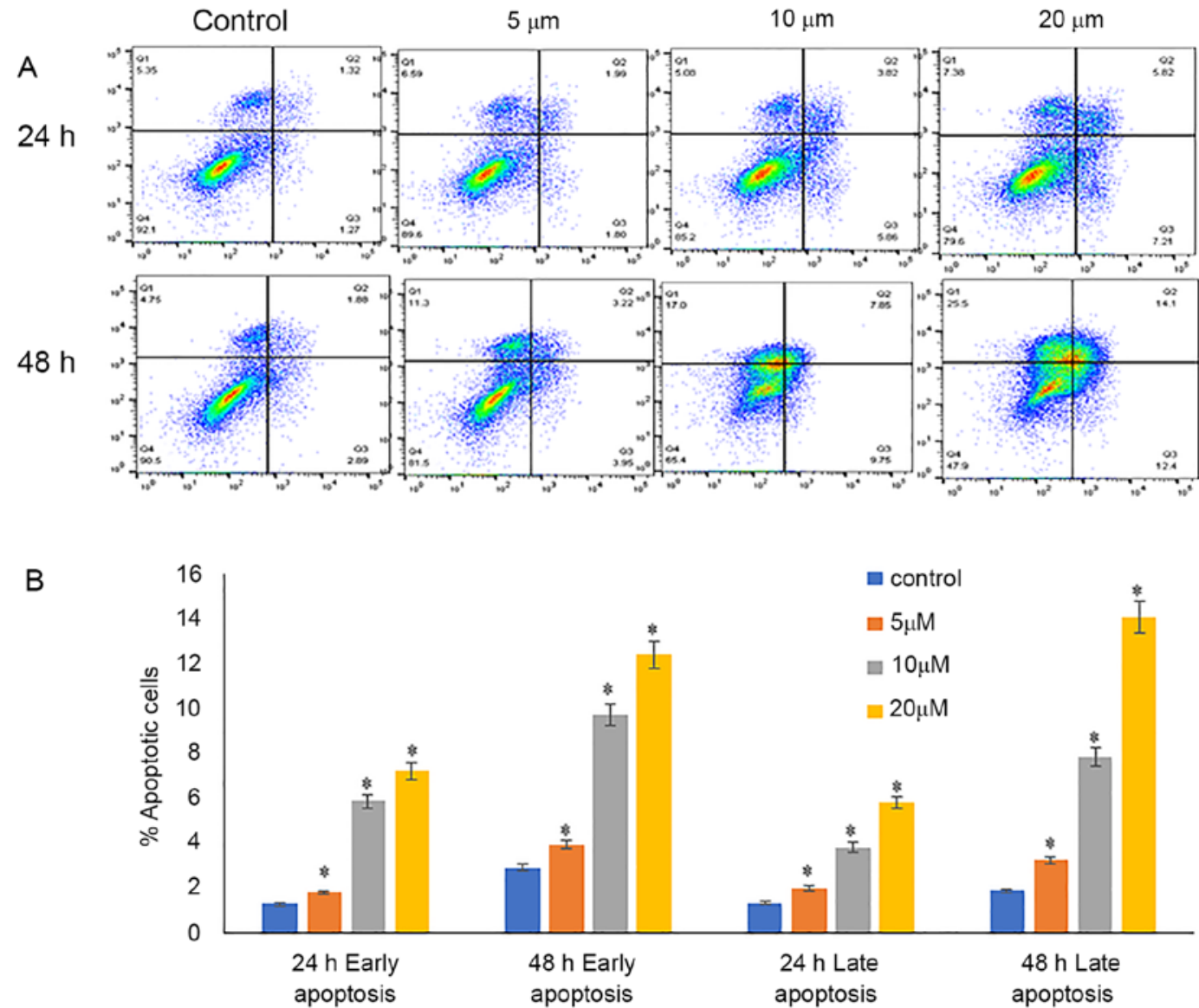

Figure 3. Evaluation of apoptosis using Annexin V-PI double staining following treatment of HeLa cells with 5,10 and $20 \mu \mathrm{M}$ luteolin for 24 and $48 \mathrm{~h}$ and DMSO control cells. (A) Representative flow cytometry dot plots of apoptosis. In all four plots, viable cells are seen in the left lower quadrant (FITC-/PI-), early apoptotic cells in the right lower quadrant (FITC+/PI-), and late apoptotic cells in the right upper quadrant (FITC+/PI+). (B) Quantification of the proportion of cells in different stages of apoptosis, as determined by flow cytometry. The proportion of early and late apoptotic cells increased in a dose-dependent manner, compared with DMSO control cells. Data are presented as the mean \pm standard deviation of three independent experiments ${ }^{*} \mathrm{P}<0.05$. DMSO, dimethyl sulfoxide.
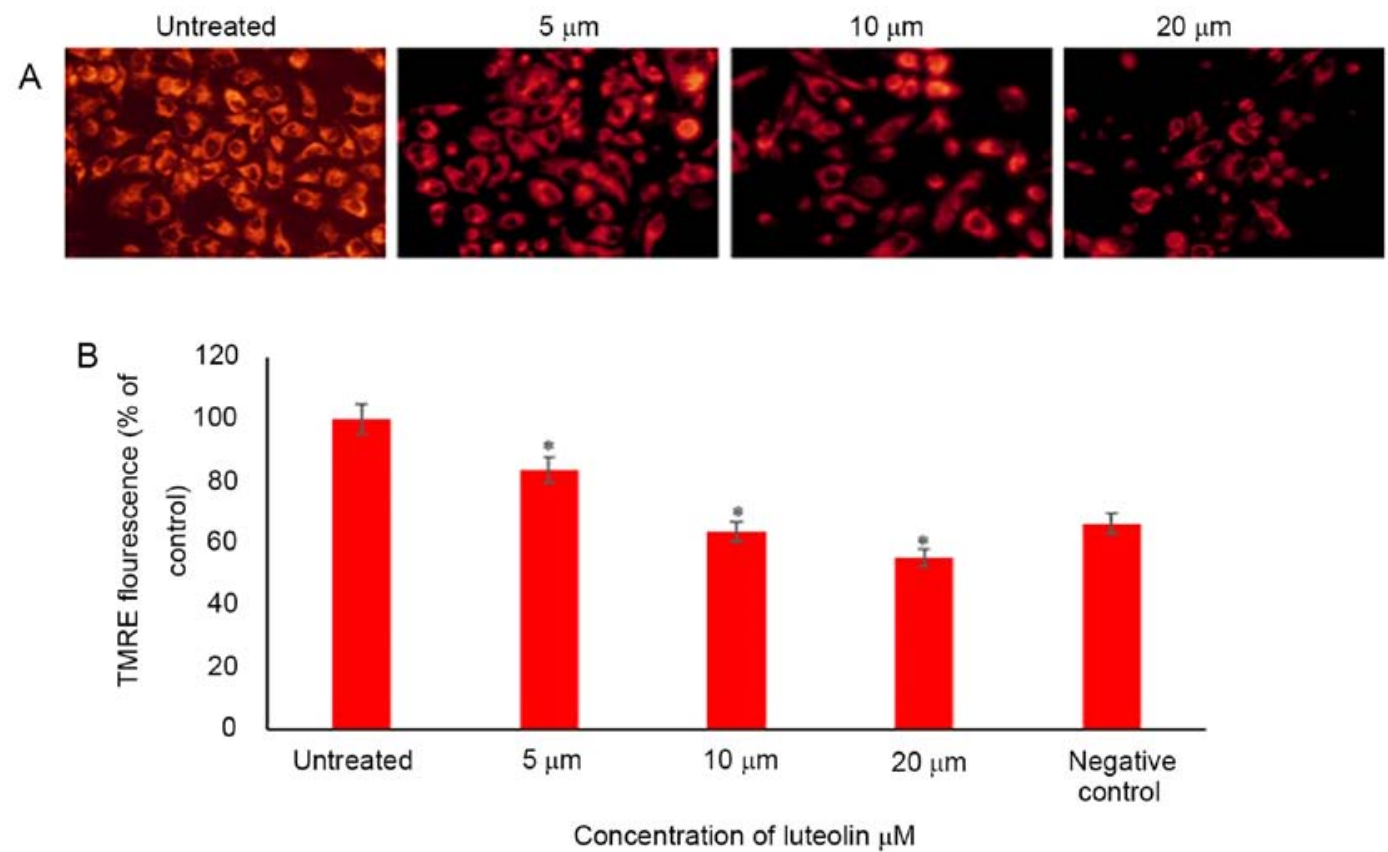

Figure 4. Luteolin decreases the membrane potential of HeLa cells in a concentration-dependent manner. (A) HeLa cells were treated with 5, 10 and $20 \mu \mathrm{M}$ luteolin for $48 \mathrm{~h}$, and the mitochondrial membrane potential was determined using TMRE staining and a fluorescent microscope (magnification, $\mathrm{x} 40$ ). (B) TMRE fluorescence of treated cells was compared with the untreated control cells and the results are expressed as the percentage of fluorescence. Data are presented as the mean \pm standard deviation of three independent experiments ${ }^{*} \mathrm{P}<0.05$. 
Table I. Relative quantitation values of cell cycle regulatory genes and pathway genes in HeLa cells following 10 and $20 \mu \mathrm{M}$ luteolin treatment for $48 \mathrm{~h}$.

\begin{tabular}{|c|c|c|c|c|}
\hline Genes & Gene ensemble no. & Gene description & Luteolin $10 \mu \mathrm{M}$ & Luteolin $20 \mu \mathrm{M}$ \\
\hline CDK4 & Hs00175935_m1 & Cyclin dependent kinase inhibitor 1A & 0.06 & 0.04 \\
\hline ESR1 & Hs01046816_m1 & Estrogen receptor 1 & 0.12 & 0.04 \\
\hline MTOR & Hs00234522_m1 & Mechanistic target of rapamycin & 0.23 & 0.18 \\
\hline PIK3C2B & Hs00898499_m1 & $\begin{array}{l}\text { Phosphatidylinositol-4-phosphate } 3 \text {-kinase } \\
\text { catalytic subunit type } 2 \text { beta }\end{array}$ & 0.37 & 0.10 \\
\hline CCNE2 & Hs00372959_m1 & Cyclin E2 & 0.39 & 0.28 \\
\hline CCND3 & Hs00236949_m & Cyclin D3 & 0.45 & 0.24 \\
\hline CDK2 & Hs01548894_m1 & Cyclin-dependent kinase 2 & 0.45 & 0.42 \\
\hline MAPK3 & Hs00385075_m1 & Mitogen-activated protein kinase 3 & 0.45 & 0.19 \\
\hline AKT2 & Hs01086102_m1 & AKT serine/threonine kinase 2 & 0.45 & 0.30 \\
\hline ELK1 & Hs00428286_g1 & ELK1C & 0.48 & 0.25 \\
\hline CCND1 & Hs00765553_m1 & Cyclin D1 & 0.50 & 0.31 \\
\hline MAPK1 & Hs01046830_m1 & Mitogen-activated protein kinase 1 & 0.50 & 0.18 \\
\hline AKT1 & Hs00178289_m1 & AKT serine/threonine kinase 1 & 0.52 & 0.31 \\
\hline TERT & Hs00972650_m1 & Telomerase reverse transcriptase & 0.53 & 0.40 \\
\hline PIK3CA & Hs00907957_m1 & Phosphatidylinositol-4C & 0.53 & 0.35 \\
\hline CCND2 & Hs00153380_m1 & Cyclin D2 & 0.60 & 0.25 \\
\hline MAPK14 & Hs00176247_m1 & Mitogen-activated protein kinase 14 & 0.60 & 0.32 \\
\hline MAP3K5 & Hs00178726_m1 & Mitogen-activated protein kinase kinase kinase 5 & 0.69 & 0.40 \\
\hline PIK3CD & Hs00192399_m1 & Phosphatidylinositol-4 & 0.71 & 0.23 \\
\hline TP53 & Hs01034249_m1 & Tumor protein $\mathrm{p} 53$ & 1.20 & 2.23 \\
\hline FOXO3 & Hs00818121_m1 & Forkhead box $\mathrm{O} 3$ & 1.60 & 4.10 \\
\hline FOXO1 & Hs00231106_m1 & Forkhead box $\mathrm{O} 1$ & 1.90 & 4.70 \\
\hline TP73 & Hs01056231_m1 & Tumor protein $\mathrm{p} 73$ & 2.80 & 5.40 \\
\hline PTPRR & Hs00373136_m & Protein tyrosine phosphatase & 9.50 & 10.00 \\
\hline
\end{tabular}

$\mathrm{RQ} \geq 2$ ), while expression of $B C L 2$ and $M C L-1$ expression was decreased in a dose-dependent manner $(20 \mu \mathrm{M}, \mathrm{RQ} \leq 0.5)$, and NAIP demonstrated a marginal decrease in expression. Notably, the receptors and ligands responsible for stimuli-based apoptosis, including FAS, FASL, FADD, TNF, TNFRSF10B, TNFRSF1A, Caspase- 8 and Caspase-8AP2 (RQ $\geq 2)$ were found to be increased in a dose-dependent manner following luteolin treatment as shown in Fig. 5B (RQ values in Table II).

Luteolin increases Caspase-3 activity in HeLa cells. Caspases are vital proteins that modulate the apoptotic response. Caspase 3 is the primary effector molecule, with the crucial role of induction of the extrinsic and intrinsic pathway of apoptosis (35). Luteolin treatment upregulated Caspase-3 activity in HeLa cells, and the activity increased in a dose-dependent manner. Luteolin-treated HeLa cells exhibited increased expression of Caspase-3 activity by 2-, 4- and 8-fold when treated with 5, 10 and $20 \mu \mathrm{M}$ luteolin for $48 \mathrm{~h}$, respectively. The increase in Caspase activity following luteolin treatment, in comparison to the control, is shown in Fig. 5C.

Luteolin alters protein expression of apoptotic genes. The fold-changes of 35 proteins that are involved in apoptosis, were investigated using an R\&D proteome profiler. Protein concentration was quantified using a Pierce BCA assay
(Thermo Fisher Scientific, Inc.; cat. no. 23225). Luteolin significantly upregulated the levels of the pro-apoptotic proteins involved in mitochondrial apoptosis, including HSP60, BAD, p-p53 (S15), BAX, SMAC/Diablo, pro-Caspase-3, Cytochrome c and HTRA2/Omi, as well as increasing the expression of receptors and ligands responsible for receptor based apoptosis, including TNF RI/TNFRSF1A, TRAIL R2/DR5, Fas/TNFRSF6/CD95, FADD, p-p53 (S392), p-RAD-17 (S635), HSP27, TRAIL R1/DR4, Catalase, p-Rad17 (S635) and cleaved-Caspase3 (all exhibiting a fold-change $\geq 1.5$-fold with $20 \mu \mathrm{M}$ luteolin treatment), while the levels of the anti-apoptotic proteins, including Pon2, BCL-X, cIAP-2, Clusterin, p27/Kip1, HIF-1 $\alpha$, BCL2, cIAP-1, Claspin and XIAP were all downregulated (all exhibiting a fold-change $\leq 0.5$ with $20 \mu \mathrm{M}$ luteolin treatment); only HSP70 expression was marginally decreased (Fig. 6; fold-changes are presented in Table III).

Luteolin modulates the Ras-Raf/MAPK and AKT/MTOR/PIK3 pathways. The MAPK and the PI3K/AKT/MTOR pathways serve a crucial role in the regulation of cell growth, differentiation and cell viability. Cancer development is associated with aberrant activation of genes in these pathways, and this may lead to increased cell proliferation and survival. Treatment of HeLa cells with 10 and $20 \mu \mathrm{M}$ luteolin for $48 \mathrm{~h}$ caused 


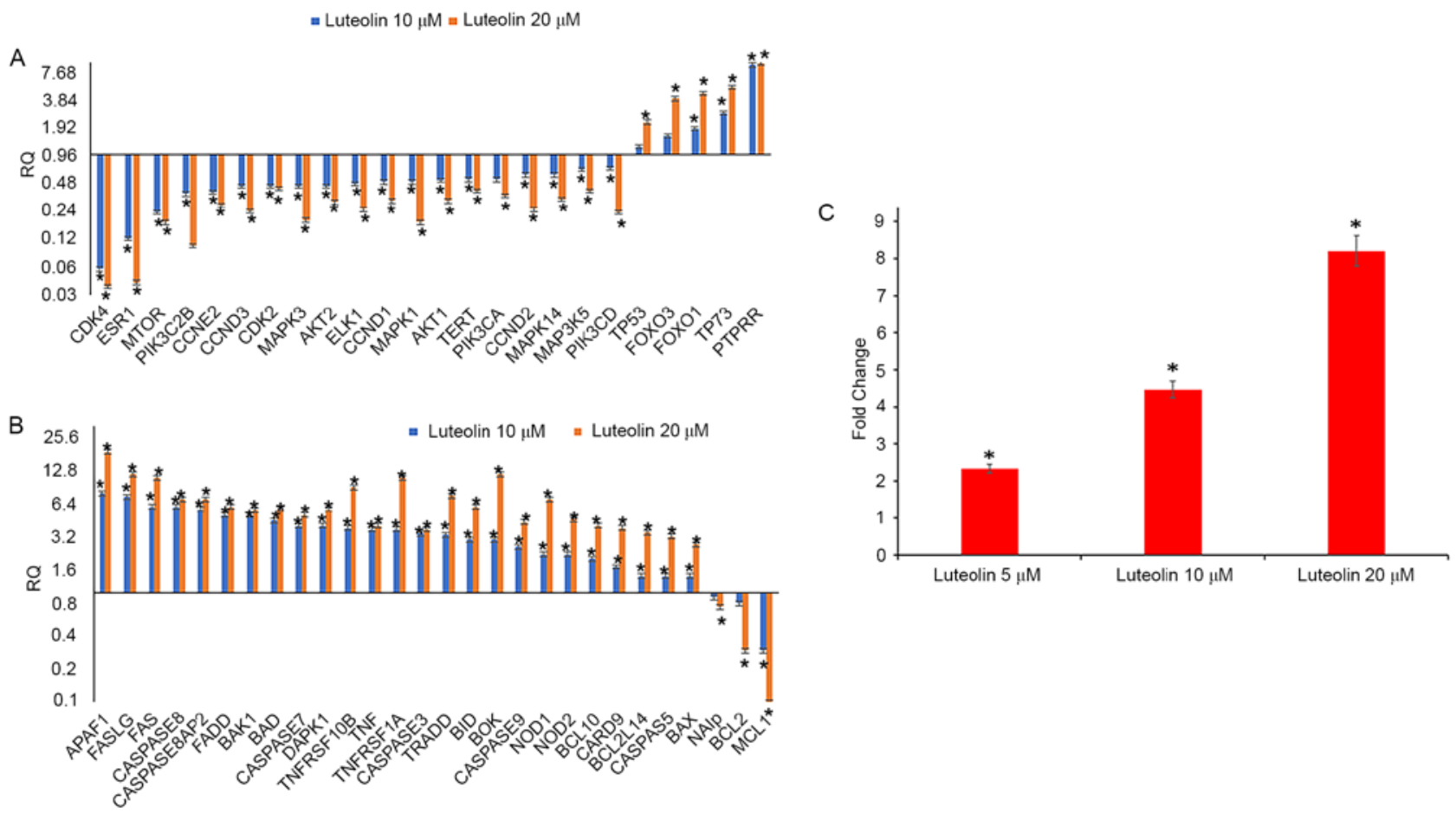

Figure 5. Treatment of HeLa cells with 10 and $20 \mu \mathrm{M}$ luteolin for $48 \mathrm{~h}$ resulted in a decrease in various cell cycle regulatory, AKT/MAPK pathway and apoptotic genes in a dose-dependent manner. (A) Decrease in cell cycle regulatory and AKT/PI3K and MAPK pathway genes. (B) Increase in the RQ values of pro-apoptotic genes and downregulation of anti-apoptotic genes following treatment with 10 and $20 \mu \mathrm{M}$ luteolin for $48 \mathrm{~h}$. The results were normalised using the endogenous control, GAPDH, and the expression in treated samples was compared with DMSO control samples. (C) Analysis of Caspase 3 activity following treatment with 5, 10 and $20 \mu \mathrm{M}$ luteolin for $48 \mathrm{~h}$. Luteolin treatment of HeLa cells increases the caspase activity by 2-, 4- and 8-fold following treatment with 5,10 and $20 \mu \mathrm{M}$ for $48 \mathrm{~h}$, respectively. Results depict the caspase activity of treated samples as compared with the DMSO controls. Data are presented as the mean \pm standard deviation of three independent experiments ${ }^{*} \mathrm{P}<0.05$. RQ, relative quantitation.

decreased expression of MAPK pathway genes, including $M A P K 1, M A K 14, M A P K 3$ and MAP3K5, as well as decreased expression of AKT/MTOR/PIK3 pathway genes, such as AKT1, AKT2, MTOR, PIK3CD, PIK3C2A and PIK3C2B (all with an $\mathrm{RQ} \leq 0.5$; Fig. 5A and Table I).

Luteolin alters the phosphorylation of proteins involved in the AKT signaling pathway. An AKT pathway phosphorylated array (cat. no. AAH-AKT-1-8) was used to assess the effects of luteolin treatment on phosphorylation of proteins involved in the AKT pathway. AKT pathway genes were modulated following treatment with 10 and $20 \mu \mathrm{M}$ of luteolin for $48 \mathrm{~h}$. Certain proteins, including P53 (p-ser241) and P27 (p-Thr198) exhibited a marginal increase in fold-change, while others, including GSK3a (p-ser21) and GSK3b (p-ser9) were not affected by luteolin treatment. MTOR (p-ser2448), PRAS 40 (p-Ther246), BAD (p-ser112), PTEN (p-ser380), AKT (p-ser473), ERK2 (p-Y185/Y18, RISK2 (p-ser386), P70S6k (p-Thr421/ser424, PDK1 (p-ser241) and ERK1 (p-T202/Y204) were downregulated. The fold-changes with respect to the control are presented in Fig. 7 and Table IV.

\section{Discussion}

Despite advances in the early detection of cancer, and developments in the prevention and treatment of cancer, it still remains the principal cause of death worldwide (37). Cancer treatment includes a wide range of chemotherapeutic drugs administered either alone or as an adjuvant with surgery or radiotherapy, and they are extremely effective in killing highly proliferative cells, including normal cells, and this underlies many of the associated side effects $(19,29,37,38)$. These drawbacks highlight the requirement for more specific and less toxic cancer treatment strategies, including plant-derived chemopreventative agents. Several studies have demonstrated that plant derived bioactive compounds exert their effects at various stages of cancer, including initiation, promotion and progression, and may serve as promising preventative or therapeutic agents. There is a strong association between a high intake of fruits and vegetables and a decreased risk of cancer $(5,10,11)$. Various dietary agents, including curcumin, resveratrol, genistein, chrysin, sulforaphane and various other flavonoids possess the ability to reverse or attenuate aberrantly active signaling pathways associated with carcinogenesis (19,28,38-42). Flavones exhibit strong anticancer effects in a range of cancer cell lines via regulation of various molecular mechanisms $(14,24,25,43)$. In addition to their ability to restore the aberrant signaling of pathways associated with cancer, flavones may cause cell cycle arrest, induce apoptosis, and inhibit invasion, metastasis and inflammation $(14,19)$. Cancer cells may evade apoptosis; therefore, apoptosis induction by the therapeutic regimen is required, and this is possible through administration of several different flavones $(14,19,43)$.

The aim of the present study was to determine the molecular mechanisms regulated by luteolin in human cervical cancer cells. Luteolin is the major bioactive compound found in several different fruits and vegetables, including oregano, 
Table II. Relative quantitation values of apoptotic genes in HeLa cells following treatment with 10 and $20 \mu \mathrm{M}$ luteolin treatment for $48 \mathrm{~h}$.

\begin{tabular}{|c|c|c|c|c|}
\hline Genes & Ensemble gene no. & Gene description & Luteolin $10 \mu \mathrm{M}$ & Luteolin $20 \mu \mathrm{M}$ \\
\hline APAF1 & Hs00559441_m1 & Apoptotic peptidase activating factor 1 & 8.00 & 19.00 \\
\hline FASLG & -Hs00181225_m1- & Fas ligand (TNF)superfamily & 7.40 & 12.00 \\
\hline FAS & Hs00163653_m1 & Fas (TNF receptor superfamily & 6.00 & 11.00 \\
\hline CASPASE 8 & Hs01018151_m1 & Caspase 8 & 6.00 & 7.00 \\
\hline CASPASE 8AP2 & Hs01594281_m1 & CASP8 associated protein 2 & 5.70 & 7.00 \\
\hline FADD & Hs00538709_m1 & Fas (TNFRSF6)-associated via death domain & 5.00 & 6.00 \\
\hline BAK1 & Hs00832876_g1 & BCL2-antagonist/killer 1 & 5.00 & 5.60 \\
\hline BAD & Hs00188930_m1 & BCL2-antagonist of cell death & 4.50 & 5.70 \\
\hline CASPASE 7 & -Hs00169152_m1 & Caspase 7 & 4.00 & 5.00 \\
\hline DAPK1 & Hs00234480_m1 & Death-associated protein kinase 1 & 4.00 & 5.70 \\
\hline TNFRSF10B & Hs00366272_m1 & Tumor necrosis factor receptor superfamily & 3.80 & 9.00 \\
\hline TNF & Hs00174128_m1 & Tumor necrosis factor (TNF superfamily & 3.70 & 4.00 \\
\hline TNFRSF1A & Hs01042313_m1 & Tumor necrosis factor receptor superfamily & 3.70 & 11.00 \\
\hline CASPASE 3 & Hs00234387_m1 & Caspase 3 & 3.40 & 3.70 \\
\hline TRADD & Hs00182558_m1 & TNFRSF1A-associated via death domain & 3.30 & 7.60 \\
\hline BID & Hs00609632_m1 & BH3 interacting domain death agonist & 3.00 & 6.00 \\
\hline $\mathrm{BOK}$ & Hs00261296_m1 & BCL2-related ovarian killer & 3.00 & 12.00 \\
\hline CASPASE 9 & Hs00154260_m1 & Caspase 9 & 2.60 & 4.30 \\
\hline NOD1 & Hs00196075_m1 & Nucleotide-binding oligomerization domain 1 & 2.20 & 7.00 \\
\hline NOD2 & Hs00223394_m1 & Nucleotide-binding oligomerization domain 2 & 2.20 & 4.60 \\
\hline BCL10 & Hs00961847_m1 & B-cell CLL/lymphoma 10 & 2.00 & 4.00 \\
\hline CARD9 & Hs00261581_m1 & caspase recruitment domain family & 1.70 & 3.80 \\
\hline BCL2L14 & Hs00373302_m1 & BCL2-like 14 (apoptosis facilitator) & 1.40 & 3.50 \\
\hline CASP 5 & Hs00362072_m1 & Caspase 5 & 1.40 & 3.20 \\
\hline BAX & Hs00751844_s1 & BCL2-associated X protein & 1.40 & 2.70 \\
\hline NAIp & Hs01847653_s1 & NRL family & 0.90 & 0.74 \\
\hline BCL2 & Hs00608023_m1 & B-cell CLL/lymphoma 2 & 0.80 & 0.29 \\
\hline MCL1 & Hs00172036_m1 & $\begin{array}{l}\text { Myeloid cell leukemia sequence } 1 \\
\text { (BCL2-related) }\end{array}$ & 0.29 & 0.10 \\
\hline
\end{tabular}
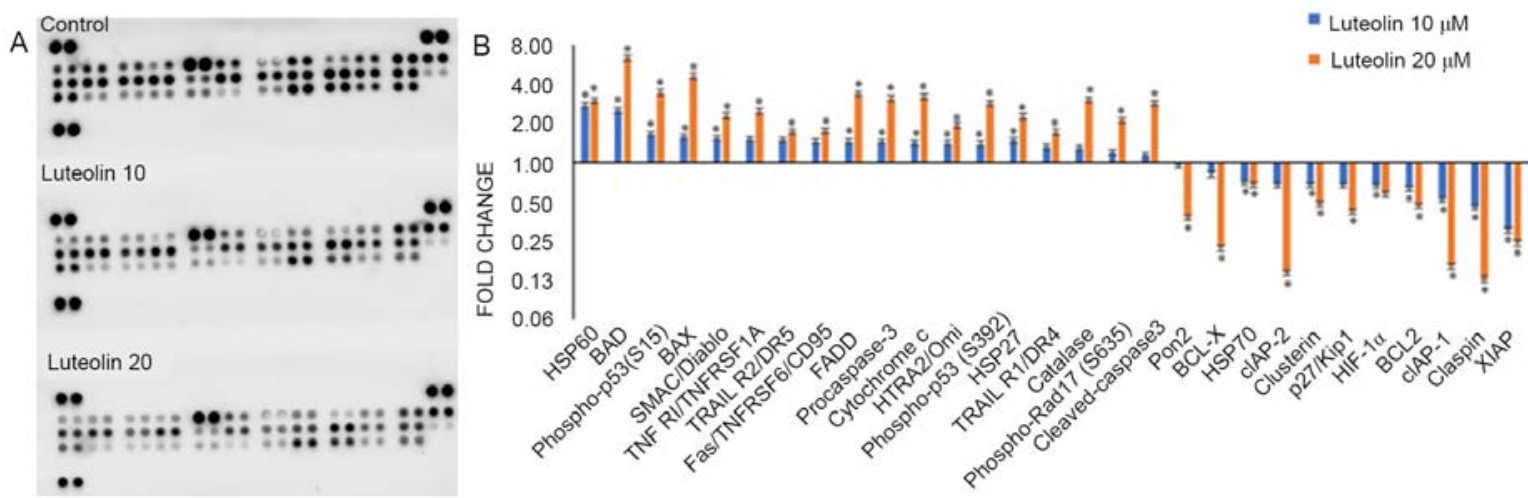

Figure 6. Change in expression of apoptotic proteins following treatment with luteolin. (A) Images of the nitrocellulose proteome profiler membrane showing differences in the expression of apoptotic and cell cycle regulatory proteins in the control and treated samples. (B) Luteolin-treated (10 and $20 \mu \mathrm{M}$ for $48 \mathrm{~h}$ ) HeLa cells exhibited upregulated expression of pro-apoptotic proteins and downregulation of anti-apoptotic proteins in a concentration-dependent manner. Fold-changes of various apoptotic proteins was quantitated by comparison with the dimethyl sulfoxide controls. The data are expressed as the mean \pm standard deviation of three independent experiments. ${ }^{*} \mathrm{P}<0.05$.

parsley and artichoke, and it possesses anti-neoplastic, anti-inflammatory, anti-microbial, anti-viral and anti-diabetic properties in vitro and in vivo $(19,24,26,27,44)$. The present study demonstrated that luteolin increased cell death in a 
Table III. Fold-change in expression of apoptotic proteins following luteolin treatment (10 and $20 \mu \mathrm{M}$ for $48 \mathrm{~h}$ ).

\begin{tabular}{|c|c|c|}
\hline Gene & $\begin{array}{c}\text { Luteolin } \\
10 \mu \mathrm{M}\end{array}$ & $\begin{array}{c}\text { Luteolin } \\
20 \mu \mathrm{M}\end{array}$ \\
\hline HSP60 & 2.73 & 2.97 \\
\hline BAD & 2.50 & 6.32 \\
\hline Phospho-p53 (S15) & 1.64 & 3.43 \\
\hline $\mathrm{BAX}$ & 1.56 & 4.58 \\
\hline SMAC/Diablo & 1.53 & 2.28 \\
\hline TNF RI/TNFRSF1A & 1.50 & 2.46 \\
\hline TRAIL R2/DR5 & 1.48 & 1.72 \\
\hline Fas/TNFRSF6/CD95 & 1.44 & 1.75 \\
\hline FADD & 1.44 & 3.36 \\
\hline Procaspase-3 & 1.43 & 3.08 \\
\hline Cytochrome c & 1.41 & 3.20 \\
\hline HTRA2/Omi & 1.40 & 1.94 \\
\hline Phospho-p53 (S392 & 1.38 & 2.85 \\
\hline HSP27 & 1.47 & 2.24 \\
\hline TRAIL R1/DR4 & 1.31 & 1.71 \\
\hline Catalase & 1.29 & 3.03 \\
\hline Phospho-Rad17 (S635) & 1.20 & 2.10 \\
\hline Cleaved Caspase 3 & 1.15 & 2.85 \\
\hline Pon2 & 0.95 & 0.38 \\
\hline BCL-X & 0.82 & 0.22 \\
\hline HSP70 & 0.70 & 0.67 \\
\hline cIAP-2 & 0.68 & 0.14 \\
\hline Clusterin & 0.67 & 0.48 \\
\hline p27/Kip1 & 0.67 & 0.42 \\
\hline $\mathrm{HIF}-1^{\alpha}$ & 0.66 & 0.57 \\
\hline BCL2 & 0.63 & 0.47 \\
\hline cIAP-1 & 0.52 & 0.16 \\
\hline Claspin & 0.45 & 0.13 \\
\hline XIAP & 0.30 & 0.24 \\
\hline
\end{tabular}

dose- and time-dependent manner, and the $\mathrm{IC}_{50}$ was $20 \mu \mathrm{M}$ at $48 \mathrm{~h}$. Treatment of HeLa cells with luteolin caused cell death that was clearly visible using a microscope, with dying cells exhibiting rounding off and detaching from the culture plates. This is in agreement with several other studies, which have demonstrated that luteolin inhibits the growth of cancer cells, with an $\mathrm{IC}_{50}$ ranging between 10 and $60 \mu \mathrm{M}$ based on cell line $(24,29,43-47)$. The changes to nuclear morphology of HeLa cells treated with 10 and $20 \mu \mathrm{M}$ for $48 \mathrm{~h}$ also justifies the assumption that apoptosis was induced by luteolin, as nuclear condensation, disintegration, nuclear blebbing and nuclear debris formation were visualized following luteolin treatment, while untreated cells did not show any significant changes in nuclear morphology. Several studies have reported that flavones, including luteolin, show similar nuclear morphological changes in several cancer cell lines, including HeLa, glioma, EC1 and KYSE450 cells $(20,24,48)$.

DNA fragmentation is a characteristic feature of apoptotic cells (33), and this was evident in luteolin treated HeLa cells. Exposure of HeLa cells to 5, 10 and $20 \mu \mathrm{M}$ luteolin for $48 \mathrm{~h}$
Table IV. Fold changes observed following treatment of HeLa cells with luteolin concentrations of 10 and $20 \mu \mathrm{M}$ for $48 \mathrm{~h}$.

\begin{tabular}{lcc}
\hline Gene & $\begin{array}{c}\text { Luteolin } \\
10 \mu \mathrm{M}\end{array}$ & $\begin{array}{c}\text { Luteolin } \\
20 \mu \mathrm{M}\end{array}$ \\
\hline P53(P-ser241) & 1.46 & 1.57 \\
P27(P-Thr198) & 1.48 & 1.57 \\
GSK3b(P-ser9) & 0.98 & 0.68 \\
Mtor(P-ser2448) & 0.67 & 0.48 \\
PRAS 40(P-ther246) & 0.67 & 0.57 \\
BAD(p-ser112) & 0.56 & 0.45 \\
PTEN(P-ser380) & 0.62 & 0.51 \\
AKT(P-ser473) & 0.80 & 0.48 \\
ERK2(P-Y185/Y187 & 0.80 & 0.50 \\
RISK2(P-ser386) & 0.66 & 0.51 \\
P70S6k(P-Thr421/ser424 & 0.70 & 0.48 \\
PDK1(P-ser241) & 0.70 & 0.48 \\
ERK1(p-T202/Y204) & 0.65 & 0.50 \\
\hline
\end{tabular}

resulted in disintegration of the DNA in a ladder-like pattern, while intact DNA was observed in the untreated control. The degree of fragmentation increased in a dose-dependent manner when treated for $48 \mathrm{~h}$. Flavonoids, including chrysin and quercetin, have also been demonstrated to fragment DNA in different cell lines $(20,23,49,50)$. Cell cycle analysis revealed that luteolin induced sub-G1 arrest following treatment with $20 \mu \mathrm{m}$ for $48 \mathrm{~h}$, in agreement with previous studies, where arrest at the $\mathrm{G} 2 / \mathrm{M}$ or $\mathrm{G} 1$ phase was observed when treated with luteolin in several different cell lines $(14,22,24,27,43)$. The determination of membrane potential using TMRE and apoptosis induction by Annexin/PI also supported the notion that apoptosis was induced by luteolin. Treatment with 5,10 or $20 \mu \mathrm{m}$ luteolin for $48 \mathrm{~h}$ resulted in mitochondrial depolarization and Annexin/PI staining showed an increase in the proportion of cells in early and late apoptosis, and this increased in a dose-dependent manner. Several studies have reported that flavonoids induce DNA fragmentation, decrease mitochondrial potential and increase the proportion of early and late apoptotic cells in various cancer cell lines $(20,24,50,51)$. Notably, it has also been demonstrated that luteolin decreased the expression levels of important cell cycle regulatory genes, including CCND2, CCND3, CCND1, CCNE2, CDK2, CDK4 and TERT, and increased the expression of $\mathrm{FOXO1}$ and $\mathrm{FOXO3}$. The cyclin D proteins, $C C N E 2$ along with $C D K 4 / C D K 6$ complex, promotes progression through the G1-S phase by inhibiting the retinoblastoma protein. $h T E R T$ is responsible for maintenance of the telomeric ends of the chromosome, and thus, its downregulation assists in the arrest of cell cycle progression, and similar results have been reported in different cell lines following treatments with polyphenols $(20,52,53)$. FOXO1/3 are considered tumor suppressors that increase transcription of pro-apoptotic, DNA damage repair and cell cycle regulatory genes, and their expression is decreased in various cancer cell lines $(20,54)$. FOXO1 is involved in tumor progression and is significantly associated with late-stage tumors, and 
A

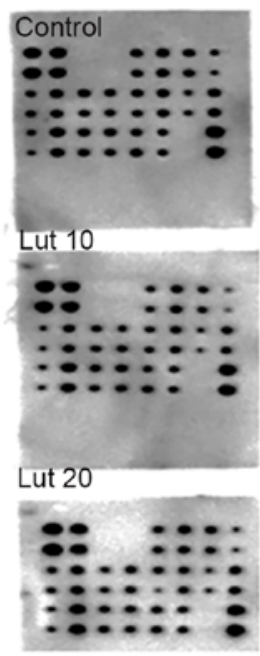

B

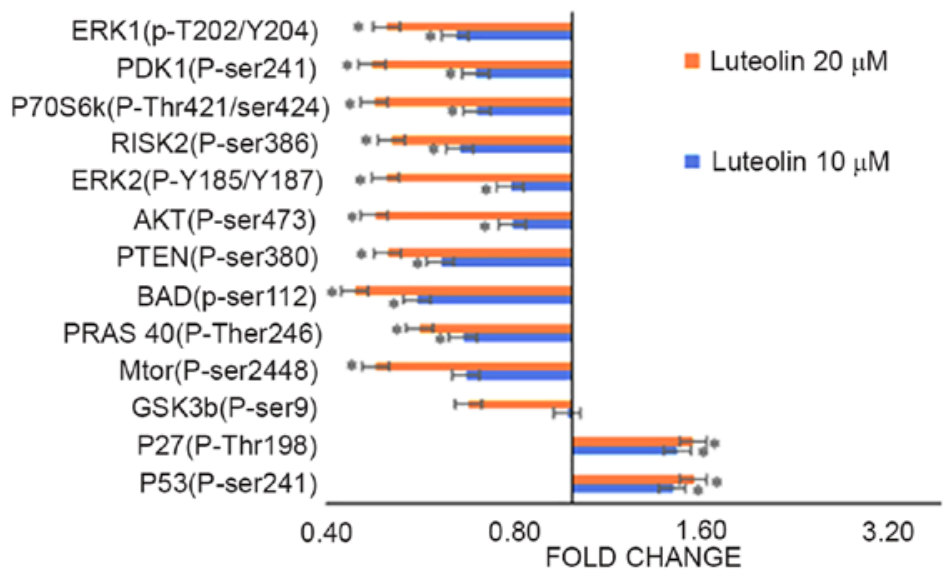

Figure 7. Differential expression of phosphorylated proteins in the AKT pathway. (A) Images of the AKT profiler membranes showing differential expression of the phosphorylated proteins involved in the AKT signaling pathway at 10 and $20 \mu \mathrm{M}$ of luteolin treatment for $48 \mathrm{~h}$. (B) Luteolin treatment decreased expression of phosphorylated proteins involved in the AKT signaling pathway, including MTOR (p-ser2448), PRAS 40 (p-Ther246), BAD (p-ser112), PTEN (p-ser380), AKT (p-ser473), ERK2 (p-Y185/187), RISK2 (p-ser386), P70S6k (p-Thr421/ser424), PDK1 (p-ser241) and ERK1 (p-T202/Y204), while the expression of P53 (p-ser241) and P27 (p-Thr198) was increased, all in a dose-dependent manner (10 and $20 \mu \mathrm{M})$. The fold-changes were calculated by comparing the treated samples with the DMSO controls. Data are presented as the mean \pm standard deviation of three independent experiments * $\mathrm{P}<0.05$.

its expression is important in terms of prognosis of cervical cancer $(20,55)$.

Pro-apoptotic and anti-apoptotic genes are the primary proteins involved in regulation of apoptosis, and they form part of the intrinsic and extrinsic apoptotic pathways. Aberrant expression of these genes contributes toward the process of carcinogenesis; therefore, these genes may be targeted for the prevention and treatment of cancer $(20,24,51)$. Luteolin treatment of HeLa cells resulted in upregulation of pro-apoptotic genes involved in the mitochondrial apoptosis pathway, including $A P A F 1, B A X, B A K 1, B A D, B I D, B O K$, Caspase7, Caspase9, Caspase 3, NOD1, NOD2, BCL10, CARD9, BCL2L14 and Caspase 5, as well as extrinsic pathway genes, including FASLG, FAS, Caspase 8, Caspase 2, FADD, TNFRSF10B, TNF, TNFRSF1A and TRADD, at the transcriptional level. By contrast, anti-apoptotic genes, including BCL2, Mcll and NAIP were found to be downregulated in luteolin-treated HeLa cells. Caspase- 3 is the primary effector caspase and serves a significant role in the induction of apoptosis via regulation of the extrinsic and intrinsic pathways. Treatment with 5, 10 and $20 \mu \mathrm{M}$ luteolin for $48 \mathrm{~h}$ enhanced the biochemical activity of Caspase- 3 by 2 , 4 and 8 -fold, respectively. The association of caspase 3 activation with decreased cell survival could be hypothesized by treating the cells with caspase inhibitor (Z-VAD-FMK), but that was beyond the scope of the present study. However, Islam et al (35) has reported role of Caspase-3 in EGCG mediated apoptosis of Human Chondrosarcoma Cells (HTB-94). Numerous studies have demonstrated that flavonoids induce apoptosis by either the intrinsic or extrinsic pathways $(14,19,20,22,48)$. Additionally, protein expression of various genes was in agreement with the changes observed in their gene expression levels. Treatment of HeLa cells with luteolin resulted in the upregulation of pro-apoptotic genes at the protein level, including upregulation of HSP60, BAD, p-p53(S15), BAX, SMAC/Diablo, TNF, RI/TNFRSF1A,
TRAILR2/DR5,Fas/TNFRSF6/CD95,FADD, pro-caspase-3, Cytochrome c, HTRA2/Omi, p-p53(S392), HSP27, TRAILR1/DR4, Catalase, p-Rad17 (S635), cleaved Caspase3 and p53, which is consistent with earlier reports on HeLa and leukemia cells treated with the flavonoids quercetin and luteolin $(17,20,23)$. Downregulation of antiapoptotic proteins at the mRNA/protein level, including Pon2, BCL-X, HSP70, cIAP-2, clusterin, p27/Kip1, HIF-1 $\alpha$, p21/CIP1/CDKN1A and $\mathrm{BCL} 2$, as well as upregulation of BAX, p-p53, release of Cytochrome C, SMAC/DIABLO and cleavage of Caspase 3, Caspase 9 and PARP1 suggests the involvement of intrinsic apoptosis. Furthermore, upregulation of receptors and ligands involved in the extrinsic pathway at the mRNA/protein level, including TNF, TNFR, RI/TNFRSF1A, TRAIL R1/DR4, TRAIL R2/DR5, Fas/TNFRSF6/CD95 and Caspase-8/Caspase-8Ap2 highlights the involvement of the extrinsic pathway. Similar results have been reported when treated with several different flavonoids and various cell lines $(19,20,56,57)$. Based on the aforementioned results, it may be stated that luteolin activates the extrinsic and the intrinsic pathway of apoptosis, in agreement with certain previous studies; however, other studies have reported that luteolin induces either the extrinsic or intrinsic pathway exclusively $(46,47,49)$. In cancer cells, alterations of p27 protein-protein interaction alters p 27 from a CDK inhibitor to an oncogene.

Activation of the AKT/RAS-RAF pathway by phosphorylation averts apoptosis; however, dephosphorylation likely induces apoptosis $(57,58)$. BAD is phosphorylated at Ser-136 and Ser-112 by AKT and RAS/RAF, respectively (58). Phosphorylation of BAD leads its association with 14-3-3 protein, whereas dephosphorylation of BAD results in its dimerization with BCL2 family proteins, and accumulation in the mitochondrial membrane, in turn increasing apoptosis (59). AKT may further activate other pathways and molecules, including the MTORC pathway (60), and is 
initiated by various growth factors and cytokines through receptor tyrosine kinases, including HER, and promotes cell survival by inactivating pro-apoptotic proteins and the forkhead (FoxO1/3a) transcription factors (61). Luteolin treatment of HeLa cells decreased the expression levels of important members of AKT/PI3K signaling; specifically, AKT1, AKT2, MTOR, PIK3CD, PIK3C2A and PIK3C2B were downregulated. Luteolin also modulated the phosphorylation of members of the AKT signaling pathway, including P53 (p-ser241) and P27 (p-Thr198), which were significantly upregulated, while GSK3b (p-ser9) was slightly downregulated, MTOR (p-ser2448), PRAS 40 (p-Ther246), BAD (p-ser112), PTEN (p-ser380) and AKT (p-ser473) were more notably downregulated, and ERK2 (p-Y185/Y187, RISK2 (p-ser386), P70S6k (p-Thr421/ser424), PDK1 (p-ser241) and ERK1 (p-T202/Y204) were significantly downregulated. Several studies have reported similar results; however, with fewer phosphorylated proteins assessed. Therefore, the present study is the first to extensively demonstrate the molecular effects of luteolin-mediated modification of phosphorylated proteins involved in the AKT pathway, to the best of our knowledge $(14,18,21)$. The MAPK pathway serves a potential role in cell proliferation and differentiation; luteolin treatment of HeLa cells showed downregulation of various members of the MAPK signaling pathway, including $M A P K 1, M A K 14, M A P K 3$ and $M A P 3 K 5$, a substantial decrease in gene expression was observed in ELK1 and ESR1 together with an increase in PTPRR, which is an inhibitor of the MAPK pathway. Notably, flavonoids have been demonstrated to inhibit the AKT/MTOR/MAPK signaling pathways through modulation of various molecules involved in these pathways $(20,22,48,49,61)$.

Plant-derived agents, such as flavonoids, including luteolin, have proven to be potentially effective options for the treatment of cancer through modulation of apoptotic pathways. However, the effect of these agents vary notably when comparing their effects in vitro and in vivo, and this may be due to their low bioavailability in vivo. Several studies have attempted to improve the bioavailability of various agents, with success in certain cases; quercetin treatment using a nano delivery system improved its effectiveness in in-vivo studies $(62,63)$. As the majority of the results cited regarding luteolin in the present study are based on in vitro and in vivo studies, and these do not necessarily always accurately represent the outcomes observed in humans, additional studies on the different pharmacokinetic parameters are required, as well as human clinical trials, before it can be considered a suitable treatment for cancer. Further study on other cancer cells, including blood tumor cells, will support the use of luteolin in a broad spectrum.

In conclusion, the various effects of luteolin highlight its efficacy on the inhibition of cell proliferation, depolarization of the mitochondrial membrane potential, induction of cell cycle arrest and impeding the RAS-RAF/MAPK/AKT/PI3K signaling pathway. Therefore, induction of apoptosis in $\mathrm{HeLa}$ cells may qualify it as a potential chemo-preventive agent. However, it is first necessary to perform additional in vivo studies and clinical trials to standardize the dosage and assess the safety of luteolin, before it can be recommended as a treatment for cervical cancer treatment.

\section{Acknowledgements}

Not applicable..

\section{Funding}

The present study was supported by the Zayed University (RIF grant no. R19056) and a MAHE internal research grant (grant no. R\&DP/MUD/RL-06/2018).

\section{Availability of data and materials}

The datasets used and/or analyzed during the present study are available from the corresponding author on reasonable request.

\section{Authors' contributions}

RR and SP performed the experiments, collected the data and wrote the manuscript. NR and $\mathrm{SH}$ revised the manuscript and validated the data. JS and KB analyzed and validated the data. $\mathrm{MH}$ and $\mathrm{AH}$ conceived and designed the study, validated the data and revised the manuscript. All authors read and approved the final manuscript.

\section{Ethics approval and consent to participate}

Not applicable.

\section{Patient consent for publication}

Not applicable.

\section{Competing interests}

The authors declare that they have no competing interests.

\section{References}

1. Tripathi KD: Essentials of medical pharmacology. 7th edition. J.P. Medical Ltd., 2013.

2. Masui K, Gini B, Wykosky J, Zanca C, Mischel PS, Furnari FB and Cavenee WK: A tale of two approaches: Complementary mechanisms of cytotoxic and targeted therapy resistance may inform next-generation cancer treatments. Carcinogenesis 34: 725-738, 2013.

3. Patterson SL, Colbert Maresso K and Hawk E: Cancer chemoprevention: Successes and failures. Clin Chem 59: 94-101, 2013.

4. Dedeurwaerder S, Defrance M, Calonne E, Denis H, Sotiriou C and Fuks F: Evaluation of the infinium methylation $450 \mathrm{~K}$ technology. Epigenomics 3: 771-784. 2011.

5. Theodoratou E, Timofeeva M, Li X, Meng X and Ioannidis JPA: Nature, nurture, and cancer risks: Genetic and nutritional contributions to cancer. Annu Rev Nutr 37: 293-320, 2017.

6. Sauter ER: Breast cancer prevention: Current approaches and future directions. Eur J Breast Health 14: 64-71, 2018.

7. de Melo FHM, Oliveira JS, Sartorelli VOB and Montor WR: Cancer chemoprevention: Classic and epigenetic mechanisms inhibiting tumorigenesis. What have we learned so far? Front Oncol 8: 644, 2018.

8. Ko JH, Sethi G, Um JY, Shanmugam MK, Arfuso F, Kumar AP, Bishayee A and Ahn KS: The role of resveratrol in cancer therapy. Int J Mol Sci 18: 2589, 2017.

9. Sur S and Panda CK: Molecular aspects of cancer chemopreventive and therapeutic efficacies of tea and tea polyphenols. Nutrition 43-44: 8-15, 2017.

10. Wu S, Zhu W, Thompson P and Hannun YA: Evaluating intrinsic and non-intrinsic cancer risk factors. Nat Commun 9: 3490, 2018. 
11. Willett WC: Diet, nutrition, and avoidable cancer. Environ Health Perspect 103 Suppl 8 (Suppl 8): S165-S170, 1995.

12. Hussain A and Raina R: Flavones combat cancer via multidimensional molecular approaches. In: Phytocompounds: Sources and Bioactivities. Studium Press, 2019.

13. Costea T, Hudiță A, Ciolac OA, Gălăteanu B, Ginghină O, Costache M, Ganea C and Mocanu MM: Chemoprevention of colorectal cancer by dietary compounds. Int J Mol Sci 19: 3787, 2018.

14. Koosha S, Alshawsh MA, Looi CY, Seyedan A and Mohamed Z: An association map on the effect of flavonoids on the signaling pathways in colorectal cancer. Int J Med Sci 13: 374-385, 2016.

15. Maru GB, Hudlikar RR, Kumar G, Gandhi K and Mahimkar MB Understanding the molecular mechanisms of cancer prevention by dietary phytochemicals: From experimental models to clinical trials. World J Biol Chem 7: 88-99, 2016.

16. Attoub S, Hassan AH, Vanhoecke B, Iratni R, Takahashi T, Gaben AM, Bracke M, Awad S, John A, Kamalboor HA, et al: Inhibition of cell survival, invasion, tumor growth and histone deacetylase activity by the dietary flavonoid luteolin in human epithelioid cancer cells. Eur J Pharmacol 651: 18-25, 2011.

17. Ham S, Kim KH, Kwon TH, Bak Y, Lee DH, Song YS, Park SH, Park YS, Kim MS, Kang JW, et al: Luteolin induces intrinsic apoptosis via inhibition of E6/E7 oncogenes and activation of extrinsic and intrinsic signaling pathways in HPV-18-associated cells. Oncol Rep 31: 2683-2691, 2014.

18. Meng G, Chai K, Li X, Zhu Y and Huang W: Luteolin exerts pro-apoptotic effect and anti-migration effects on A549 lung adenocarcinoma cells through the activation of MEK/ERK signaling pathway. Chem Biol Interact 257: 26-34, 2016.

19. Abotaleb M, Samuel SM, Varghese E, Varghese S, Kubatka P, Liskova A and Büsselberg D: Flavonoids in cancer and apoptosis. Cancers (Basel) 11: 28, 2019.

20. Kedhari Sundaram M, Raina R, Afroze N, Bajbouj K, Hamad M, Haque $\mathrm{S}$ and Hussain A: Quercetin modulates signaling pathways and induces apoptosis in cervical cancer cells. Biosci Rep 39: BSR20190720, 2019.

21. Badgujar NV, Mistry KN, Rank DN and Joshi CG: Screening of antiproliferative activity mediated through apoptosis pathway in human non-small lung cancer A-549 cells by active compounds present in medicinal plants. Asian Pac J Trop Med 11: 666-675, 2018

22. Tuorkey MJ: Molecular targets of luteolin in cancer. Eur J Cancer Prev 25: 65-76, 2016.

23. Wang SW, Chen YR, Chow JM, Chien MH, Yang SF, Wen YC Lee WJ and Tseng TH: Stimulation of Fas/FasL-mediated apoptosis by luteolin through enhancement of histone $\mathrm{H} 3$ acetylation and c-Jun activation in HL-60 leukemia cells. Mol Carcinog 57: 866-877, 2018.

24. Chen P, Zhang JY, Sha BB, Ma YE, Hu T, Ma YC, Sun H, Shi JX, Dong ZM and Li P: Luteolin inhibits cell proliferation and induces cell apoptosis via down-regulation of mitochondrial membrane potential in esophageal carcinoma cells EC1 and KYSE450. Oncotarget 8: 27471-27480, 2017.

25. Park SH, Ham S, Kwon TH, Kim MS, Lee DH, Kang JW, Oh SR and Yoon DY: Luteolin induces cell cycle arrest and apoptosis through extrinsic and intrinsic signaling pathways in MCF-7 breast cancer cells. J Environ Pathol Toxicol Oncol 33: 219-231, 2014

26. Mary V,Haris P, Varghese MK, Aparna P and Sudarsanakumar C: Experimental probing and molecular dynamics simulation of the molecular recognition of DNA duplexes by the flavonoid luteolin. J Chem Inf Model 57: 2237-2249, 2017.

27. Imran M, Rauf A, Abu-Izneid T, Nadeem M, Shariati MA, Khan IA, Imran A, Orhan IE, Rizwan M, Atif M, et al Luteolin, a flavonoid, as an anticancer agent: A review. Biomed Pharmacother 112: 108612, 2019.

28. Aggarwal R, Jha M, Shrivastava A and Jha AK: Natural compounds: Role in reversal of epigenetic changes. Biochemistry (Mosc) 80: 972-989, 2015.

29. Zhou Y, Zheng J, Li Y, Xu DP, Li S, Chen YM and Li HB: Natural polyphenols for prevention and treatment of cancer. Nutrients 8: $515,2016$.

30. Ruan J, Zhang L, Yan L, Liu Y, Yue Z, Chen L, Wang AY, Chen W, Zheng S, Wang S and Lu Y: Inhibition of hypoxia-induced epithelial mesenchymal transition by luteolin in non-small cell lung cancer cells. Mol Med Rep 6: 232-238, 2012.

31. Sundaram MK, Unni S, Somvanshi P, Bhardwaj T, Mandal RK, Hussain A and Haque S: Genistein modulates signaling pathways and targets several epigenetic markers in HeLa cells. Genes (Basel) 10: 955, 2019.

32. Masters JR: HeLa cells 50 years on: The good, the bad and the ugly. Nat Rev Cancer 2: 315-319, 2002.
33. Shariffa K: Apoptosis-journey of a cell in life. Univ J Surg Surg Spec 4: No .3, 2018.

34. Li J, Han J, Hu Y and Yang J: Selection of reference genes for quantitative real-time PCR during flower development in tree peony (Paeonia suffruticosa Andr.). Front Plant Sci 7: 516, 2016

35. Islam S, Islam N, Kermode $\mathrm{T}$, Johnstone $\mathrm{B}$, Mukhtar $\mathrm{H}$, Moskowitz RW, Goldberg VM, Malemud CJ and Haqqi TM: Involvement of caspase-3 in epigallocatechin-3-gallate-mediated apoptosis of human chondrosarcoma cells. Biochem Biophys Res Commun 270: 793-797, 2000

36. Lennarz WJ and Lane MD: Encyclopedia of biological chemistry. 2nd edition. Academic Press, 2013.

37. Gul-e-Saba, Islamiah M, Ismail N, Mohamad H, Sung YY and Muhammad TST: Induction of apoptosis by Aaptos sp., fractions in human breast cancer cell line, MCF-7. Int J Res Pharm Sci 9: No. 2, 2018

38. Lee DH, Park KI, Park HS, Kang SR, Nagappan A, Kim JA, Kim EH, Lee WS, Hah YS, Chung H, et al: Flavonoids isolated from Korea Citrus aurantium L. induce G2/M phase arrest and apoptosis in human gastric cancer AGS cells. Evid Based Complement Alternat Med 2012: 515901, 2012.

39. Abdal Dayem A, Choi HY, Yang GM, Kim K, Saha SK and Cho SG: The anti-cancer effect of polyphenols against breast cancer and cancer stem cells: Molecular mechanisms. Nutrients 8: 581, 2016.

40. Mocanu MM, Nagy P and Szöllősi J: Chemoprevention of breast cancer by dietary polyphenols. Molecules 20: 22578-22620, 2015.

41. Khan MA, Hussain A, Sundaram MK, Alalami U, Gunasekera D, Ramesh L, Hamza A and Quraishi U: (-)-Epigallocatechin-3-gallate reverses the expression of various tumor-suppressor genes by inhibiting DNA methyltransferases and histone deacetylases in human cervical cancer cells. Oncol Rep 33: 1976-1984, 2015

42. Hussain A, Mohsin J, Prabhu SA, Begum S, Nusri Qel-A, Harish G, Javed E, Khan MA and Sharma C: Sulforaphane inhibits growth of human breast cancer cells and augments the therapeutic index of the chemotherapeutic Drug, gemcitabine. Asian Pac J Cancer Prev 14: 5855-5860, 2013.

43. Xue C, Chen Y, Hu DN, Iacob C, Lu C and Huang Z: Chrysin induces cell apoptosis in human uveal melanoma cells via intrinsic apoptosis. Oncol Lett 12: 4813-4820, 2016.

44. Cao Z, Zhang H, Cai X, Fang W, Chai D, Wen Y, Chen H, Chu F and Zhang Y: Luteolin promotes cell apoptosis by inducing autophagy in hepatocellular carcinoma. Cell Physiol Biochem 43: 1803-1812, 2017

45. Hu C, Cai X, Hu T, Lu W and Cao P: Mechanism of growth inhibition effect of 3', 4', 5, 7-tetrahydroxyflavone on A549 cells. Zhongguo Zhong Yao Za Zhi 37: 1259-1264, 2012 (In Chinese).

46. Aneknan P, Kukongviriyapan V, Prawan A, Kongpetch S, Sripa B and Senggunprai L: Luteolin arrests cell cycling, induces apoptosis and inhibits the JAK/STAT3 pathway in human cholangiocarcinoma cells. Asian Pac J Cancer Prev 15: 5071-5076, 2014.

47. George VC, Naveen Kumar DR, Suresh PK, Kumar S and Kumar RA: Comparative studies to evaluate relative in vitro potency of luteolin in inducing cell cycle arrest and apoptosis in HaCaT and A375 cells. Asian Pac J Cancer Prev 14: 631-637, 2013.

48. You Y, Wang R, Shao N, Zhi F and Yang Y: Luteolin suppresses tumor proliferation through inducing apoptosis and autophagy via MAPK activation in glioma. Onco Targets Ther 12: 2383, 2019.

49. Lu X, Li Y, Li X and Aisa HA: Luteolin induces apoptosis in vitro through suppressing the MAPK and PI3K signaling pathways in gastric cancer. Oncol Lett 14: 1993-2000, 2017.

50. Samarghandian S, Nezhad MA and Mohammadi G: Role of caspases, Bax and Bcl-2 in chrysin-induced apoptosis in the A549 human lung adenocarcinoma epithelial cells. Anticancer Agents Med Chem 14: 901-909, 2014.

51. Tu LY, Bai HH, Cai JY and Deng SP: The mechanism of kaempferol induced apoptosis and inhibited proliferation in human cervical cancer SiHa cell: From macro to nano. Scanning 38: 644-653, 2016.

52. Ren X, Zhang Z, Tian J, Wang H, Song G, Guo Q, Tian J, Han Y, Liao Q, Liu G, et al: The downregulation of c-Myc and its target gene hTERT is associated with the antiproliferative effects of baicalin on HL-60 cells. Oncol Lett 14: 6833-6840, 2017.

53. Huang L, Jin K and Lan H: Luteolin inhibits cell cycle progression and induces apoptosis of breast cancer cells through downregulation of human telomerase reverse transcriptase. Oncol Lett 17: 3842-3850, 2019 . 
54. Song KH, Woo SR, Chung JY, Lee HJ, Oh SJ, Hong SO, Shim J, Kim YN, Rho SB, Hong SM, et al: REP1 inhibits FOXO3-mediated apoptosis to promote cancer cell survival. Cell Death Dis 8: e2536, 2018.

55. Zhang B, Gui LS, Zhao XL, Zhu LL and Li QW: FOXO1 is a tumor suppressor in cervical cancer. Genet Mol Res 14: 6605-6616, 2015

56. Zhang Y, Chen S, Wei C, Rankin GO, Ye X and Chen YC: Flavonoids from Chinese bayberry leaves induced apoptosis and G1 cell cycle arrest via Erk pathway in ovarian cancer cells. Eur J Med Chem 147: 218-226, 2018.

57. Srivastava S, Somasagara RR, Hegde M, Nishana M, Tadi SK, Srivastava M, Choudhary B and Raghavan SC: Quercetin, a natural flavonoid interacts with DNA, arrests cell cycle and causes tumor regression by activating mitochondrial pathway of apoptosis. Sci Rep 6: 24049, 2016.

58. Fang X, Yu S, Eder A, Mao M, Bast RC Jr, Boyd D and Mills GB: Regulation of BAD phosphorylation at serine 112 by the Ras-mitogen-activated protein kinase pathway. Oncogene 18: 6635-6640, 1999.

59. Khoo BY, Chua SL and Balaram P: Apoptotic effects of chrysin in human cancer cell lines. Int J Mol Sci 11: 2188-2199, 2010.
60. Cardoso MFS, Castelletti CHM, Lima-Filho JL, Martins DBG and Teixeira JAC: Putative biomarkers for cervical cancer: SNVs, methylation and expression profiles. Mutat Res 773: 161-173, 2017.

61. Okkenhaug K, Bilancio A, Farjot G, Priddle H, Sancho S, Peskett E, Pearce W, Meek SE, Salpekar A, Waterfield $\mathrm{MD}$, et al: Impaired $\mathrm{B}$ and $\mathrm{T}$ cell antigen receptor signaling in p110delta PI 3-kinase mutant mice. Science 297: 1031-1034, 2002.

62. Wang S, Zhang J, Chen M and Wang Y: Delivering flavonoids into solid tumors using nanotechnologies. Expert Opin Drug Deliv 10: 1411-1428, 2013.

63. Yuan ZP, Chen LJ, Fan LY, Tang MH, Yang GL, Yang HS, Du XB, Wang GQ, Yao WX, Zhao QM, et al: Liposomal quercetin efficiently suppresses growth of solid tumors in murine models. Clin Cancer Res 12: 3193-3199, 2006.

This work is licensed under a Creative Commons Attribution-NonCommercial-NoDerivatives 4.0 International (CC BY-NC-ND 4.0) License. 